\title{
Concepción filosófico-antropológica del hombre americano: la perspectiva teórica de Bartolomé de las Casas*
}

José Wilmar Pino Montoya**

\section{Resumen}

El artículo presenta la teoría del hombre de Bartolomé de las Casas sustraída principalmente de la tradición aristotélica, Tomas de Aquino, Francisco de Vitoria, del cristianismo y de su experiencia como colono y clérigo, complemento práctico que le permitieron entender al hombre americano desde una perspectiva filosófico-antropológica, con atributos particulares emanados de la misma naturaleza humana y de los contextos geográficos en los que vive. El siguiente trabajo constará de las fuentes teóricas de la cual toma Bartolomé de las Casas su filosofía sobre el hombre: Aristóteles, Tomás de Aquino; y la Biblia, para concluir con el concepto de hombre Lascasiano sustraído de la combinación de hace de las teorías leídas como de la experiencia en el territorio americano.

Palabras clave: hombre, filosófico-antropológico, América, aborigen, razón.

* Este artículo de reflexión es el resultado de la investigación: "Productos de investigación" aprobado y financiado por la Vicerrectoria de Investigaciones de la Universidad Católica Luis Amigó para el año 2017. Citar como: Pino M., J.W. (2018). Concepción filosófico-antropológica del hombre americano: la perspectiva teórica de Bartolomé de las Casas. Cuadernos de Filosofía Latinoamericana, 39(119), 77-96. DOI: http://www.doi.org/10.15332/25005375.5051

** Doctor en Filosofía de la UPB de Medellin, Magister en Educación y Desarrollo Humano de la Universidad de Manizales, Filósofo de la Universidad de Antioquia. Docente Facultad de Educación y Humanidades en la Universidad Católica Luis Amigó. Medellín, Colombia. http://orcid.org/0000-0001-9035-2058. Correo: jose.pinomo@amigo.edu.co 


\section{Philosophical-anthropological conception of the american man: the theoretical perspective of Bartolomé de las Casas}

\section{Abstract}

The article presents Bartolomé de las Casas's theory of man, mainly taken from the Aristotelian tradition, Thomas Aquinas, Francisco de Vitoria, from Christianity and from his experience as a settler and cleric, a practical complement that allowed him to understand the American man from a philosophical-anthropological perspective, with particular attributes emanating from the human nature itself and the geographical contexts in which he lives. The following work will consist of the theoretical sources from which Bartolomé de las Casas takes his philosophy on man: Aristotle, Thomas Aquinas; and the Bible, to conclude with the concept of Lascasian man taken from the combination of the theories read as of the experience in the American territory.

Keywords: Man, philosophical-anthropological, America, aboriginal, reason.

\section{Introducción}

En este trabajo, se trata de sustentar y poner de relieve la definición de hombre, en particular resaltar desde la filosofía y la antropología la definición y características del hombre americano, reflexionadas y estudiadas por Bartolomé de las Casas quien se interesó por defender los derechos de los aborígenes americanos, quienes se vieron expuestos al comportamiento conquistador de los españoles.

El fraile Dominico para sustentar y desarrollar sus premisas en defensa de los aborígenes, parte de la reflexión filosófica sustraída de la tradición Aristotélica, de Tomas de Aquino, la doctrina contenida sobre el concepto de hombre que aparece en la Biblia, las tradiciones medievales referentes a la filosofía del derecho, sustentada en la ley natural y de la experiencia que como encomendero y doctrinero tuvo en las nuevas tierras de América.

Estas reflexiones filosófico-antropológicas sobre el hombre americano fueron plasmadas y distribuidas a lo largo de toda la tradición literaria de Bartolomé de las Casas, 
quien entrelaza y desarrolla los aportes más significativos que le brindó su experiencia, con las teorías y las reflexiones que sobre el concepto de hombre le suministra Aristóteles y las consideraciones humanistas e iusnaturalistas predominantes en la Edad Media, en especial, retomando los postulados teóricos del iusnaturalismo racionalista de Tomás de Aquino, que en principio fueron asumidos por Francisco de Vitoria y posteriormente por Las Casas para, desde allí, explicar las características fundamentales de los hombres que se encontraron en las nuevas tierras. Sobre los fundamentos filosóficos que inspiraron el pensamiento de Las Casas dice Romo:

De todas las citas que Bartolomé de las Casas realiza directa o indirectamente los autores más mencionados son: Aristóteles... y Santo Tomás de Aquino. Hace alusiones directas a la ética, a la Metafísica, a la física, a la política de Aristóteles... de Santo Tomás fundamentalmente cita la Summas. (Romo, 1994, p.153)

En este marco de ideas, se argumentará y demostrará que el padre Fray Bartolomé de las Casas parte del concepto filosófico-antropológico de hombre, teoría sustraída, como ya se ha dicho, principalmente de la filosofía; de la teología y de su experiencia antropológica en las Indias. Complemento teórico-práctico que le permitieron comprender que si bien los aborígenes de América, y el hombre en general, gozan y están dotados de características y atributos iguales emanados de la misma naturaleza humana que les permite disfrutar de similares derechos en la vida, en especial de los derechos a la dignidad, la igualdad, la libertad, la propiedad, la intimidad, entre otros, los hombres encontrados y por el contexto en el que habitan se diferencian de los "europeos" en su contextura física, espiritualidad y maneras de adaptarse al medio condición que les permite comprender el mundo y ordenárselo de forma diferente al hombre por quien fue conquistado.

En este sentido, la siguiente ponencia constará de cuatro temas, que son la fuente filosófica de la cual bebe el dominico su filosofía sobre el hombre. Estos temas en su orden son: los conceptos de hombre que aparecen en las teorías de Aristóteles y Tomás de Aquino; el concepto de hombre aportado por las reflexiones bíblicas; los mismos que fueron retomados por Bartolomé de las Casas, para continuar la custodia teórica y práctica de los aborígenes del nuevo mundo. Enseguida aparecerá el concepto filosófico-antropológico de hombre sustraído, tanto de su experiencia, como de sus lecturas filosóficas. 


\section{Concepto de Hombre}

\section{Concepto de hombre en Aristóteles}

Partiendo del concepto de vida acuñado por Aristóteles, entendida como una entidad compuesta tanto de forma como de materia con la característica de poseer por sí misma automovimiento, es decir, que se da en ella: nutrición, envejecimiento y desarrollo; nace y se deriva el concepto de hombre ${ }^{1}$; que es una idea radicalmente diferente a la de hombre que se halla en Platón, ya que para éste el hombre era concebido como una consecuencia de la unión accidental entre la forma y la materia, es decir, entre el alma y el cuerpo. Es de recordar que para Platón estos dos entes eran y se percibían como dos entidades de características totalmente diferentes y que se veían obligadas a establecer una relación transitoria. Otras de las características de esta concepción platónica sobre el hombre, es que dada la relación provisional que se establece entre el alma y el cuerpo, la entidad que conforman ambas, no es una entidad que resulta del compuesto de las dos, como lo afirma Aristóteles, sino que el alma, en la concepción platónica es entendida como el timón que domina y maneja el barco, o como bien se afirma en el siguiente aparte del Fedón, en la que el alma es entendida como una entidad sujetada y recluida en el cuerpo, que es su prisión y su corrupción. Dice al respecto Platón en el diálogo del Fedón:

Los filósofos, al ver que su alma está verdaderamente ligada y pegada al cuerpo, y forzada a considerar los objetos por medio del cuerpo, como a través de una prisión oscura y no por sí misma, conocen perfectamente lo que la fuerza de este lazo corporal consiste en las pasiones, que hacen que el alma misma encadenada contribuya a apretar la ligadura. (Platón, 1992, p 151)

Como se observa en este argumento, el alma para Platón es una entidad inteligible, invisible, inmortal, simple e indisoluble que forma parte de lo divino, en tanto que el cuerpo es la entidad mortal, disoluble y siempre mutable. Así la idea de hombre para Platón está íntimamente relacionada con el concepto que este desarrolla sobre el alma, y es desde allí donde saca la idea de carácter escatológico, de que la vida del hombre está más allá

1 La definición aparece en Aristóteles no únicamente como el resultado de sus propias meditaciones, sino además como la consecuencia de una tradición filosófica que, aun sin haberse planteado ontológicamente la pregunta por el hombre, habia venido formándose una imagen de estas, imagen que encontramos subyacente en su pensamiento gnoseológico y ético. Este aparte aparece en: SIERRA MEJIA, Rubén. Hombre y Logos en Aristóteles. En: Un. Diciembre, 1970, no. 7, p. 34. 
de la vida como ser corpóreo o corruptible, pues allí se encontrará después de la muerte con la entidad de su misma naturaleza, con la libertad y con la cura para todos sus males.

Alejándose de las premisas de su maestro, Aristóteles desarrolla su concepción del hombre apoyándose en las teorías que elaboró sobre la sustancia o la entidad compuesta; para él, es imposible que se dé y que exista una sustancia formada por el alma separada de la materia. La entidad o sustancia, según el filósofo, es un compuesto de ambas formas que se complementan y se integran de manera inconmovible, y por ello y por estar integrada a la materia y estar adherida al cuerpo, está el alma aristotélica, también y al igual que la materia, está expuesta a la corrupción y a la desintegración; de lo que se interpreta que para Aristóteles al desaparecer el cuerpo o materia, también desaparece el alma o el espíritu. El hombre es entonces para este autor, una sustancia compuesta y de manera indisoluble por la materia y la forma, en la que la forma es la entelequia del cuerpo o de la materia, es decir, el alma es el principio vital del cuerpo.

No obstante, y como ya se ha mencionado, todos los seres vivos, al igual que el hombre, albergan en su composición como sustancias vivientes, tanto alma como materia. Vegetales y animales de todas las demás especies y en general, comparten con el hombre, la indisolubilidad de la unión entre cuerpo y alma; por ello existen en la clasificación aristotélica cuatro clases de almas: la vegetativa, la sensitiva, la apetitiva y la intelectiva, albergando esta última todas las demás, teniendo también la facultad de juzgar, razonar, contemplar y de construir el conocimiento y la ciencia. Son estas últimas características del alma intelectiva las que identifican en Aristóteles el concepto de hombre ${ }^{2}$, quien y además de poseer las funciones de las almas anteriores, tiene la capacidad para ejercer y ejecutar acciones racionales. Es el alma racional, entonces, el tipo de alma que le da las características propias y particulares al concepto de hombre aristotélico, ya que esta alma racional es la que lo diferencia y aleja, de manera sustancial, de los demás seres vivos.

2 Para comprender su alcance, debemos tener en cuenta que en la doctrina aristotélica la definición es la expresión en palabras de la esencia del ente definido, teoria que se mantuvo vigente hasta Locke, para quien una definición sólo indica el significado de una palabra mediante términos que no sean sinónimos. Así, pues, si la definición para Aristóteles expresa la esencia en los términos -y en la aclaración de su contenido- de la definición dada por él, hallaremos la naturaleza del hombre. Es decir, que para conocer su concepción del hombre, podemos movernos por lo pronto, en una clasificación de los términos utilizados en aquella definición. Estos términos son: zoion y logos, y en su traducción latina: animal y ratio. Véase nuevamente a: SIERRA, Op. Cit., p. 36. 
Al situar en el hombre las funciones del alma racional o intelectiva, dota a éste de la capacidad y la posibilidad de distinguir y de acceder a la verdad en sí misma, es decir, le concede el don de construir el conocimiento llamado hoy el saber científico y de utilizar éste para fines prácticos. En este sentido, es para Aristóteles el alma, no sólo la entidad que dota a la materia de principio vital o constituye para esta la entelequia, sino que es también, y en concordancia con el argumento de Platón, elemento primero e indispensable para cumplir las funciones de conocimiento ${ }^{3}$.

Se ha dicho hasta aquí que la concepción aristotélica del hombre es una concepción fundamentada en la integración de dos sustancias, a saber: el cuerpo y el alma; pero esta alma que es propia de la especie hombre, lo dota de la facultad discursiva y del intelecto. El hombre así entendido, es un conjunto sustancial de dos elementos: uno que hace las veces de cuerpo, que en este caso es la materia; y el otro que hace las veces de alma intelectiva y discursiva, llamado forma, y así es como aparece la unión sustancia dotada de razón que se llama hombre. Es en este nuevo compuesto como la forma y la materia marchan juntos en una alianza de movimiento, de operaciones, de actos y maneras de conocer que generan y dan como resultado una nueva sustancia que componen las actividades de la raza humana, en las que el conocimiento, por ser un conocimiento del hombre como tal y no meramente de la forma o del cuerpo, es adquirido, no de manera independiente por una de las entidades, sino de manera conjunta. En relación con las características propias del hombre aristotélico, dice Max Scheler:

En esta idea conviene precisar cuatro notas de importancia eminente: $1^{\circ}$ el hombre lleva en sí un agente divino que la naturaleza no contiene subjetivamente. $2^{\circ}$ ese agente se identifica ontológicamente, o por lo menos en su principio, con lo que eternamente plasma el mundo y le da forma de mundo (racionalizando en caos, convirtiendo la "materia" en cosmos); por lo tanto, ese agente es verdaderamente capaz de conocer el mundo. $3^{\circ}$ Ese agente como $\lambda$ ó os -reino de las formas "sustanciales" en Aristóteles- como razón humana, poder y fuerza aun sin los instintos y la sensibilidad (percepción, memoria, etcétera), comunes al hombre y a los animales, para realizar sus contenidos ideales (poder del espíritu, fuerza propia de la idea). $4^{\circ}$ Este agente es absolutamente constante en la historia, en los pueblos y en las clases. (Scheler, s.f. pp. 28-29)

3 Véase los estudios que sobre el logos y el nous con relación al conocimiento en la idea de hombre de Aristóteles realiza. En: Ibid., p. 38. 


\section{Concepto de hombre en Santo Tomás de Aquino}

Para adentrarse ahora en la reflexión que hace el Aquinante sobre el concepto de hombre, es pertinente acudir en primera instancia a su siguiente nota: "tras el estudio de la criatura espiritual y corporal debemos tratar ahora del hombre, ser compuesto de espíritu y materia" (De Aquino, 1985,1q.75).

Como se observa, al igual que el concepto que desarrolla sobre la vida, Tomás de Aquino en la definición que logra realizar del hombre es evidentemente aristotélico, porque toma de éste, la definición de ser humano como un compuesto o como una sustancia, a saber, integrada por cuerpo y alma o materia y forma; de allí que se apodera de la teoría helimórfica aristotélica para desarrollar la suya:

Tomas de Aquino ha descubierto en el fenómeno humano la estructura interna que lo regula. Ha continuado la tradición Aristotélica y ha aplicado al cuerpo humano la teoría helimórfica. El cuerpo ${ }^{4}$ como elemento material, está al servicio del alma, dispuesto por ella, contenido por la forma que le da el ser. En esta teoría se comprende al cuerpo no como un todo aislado, sino como un elemento de una unidad superior que hace imposible el dualismo de sustancia en el hombre. (Lobato, 1994, p. 147)

Las sustancias que componen la definición de hombre, han de unirse en una relación esencial, en la que en ausencia de una de ellas, la constitución de la sustancia: hombre, carecería de sentido. Lo anterior, quiere decir que su separación sería una limitante sustancial para realizar su función relacionada con las actividades intelectivas sensitivas y vegetativas, pues el hombre en el Aquitano, no toma su conocimiento del mundo de las ideas o del mundo metafísico, tal y como lo argumentó en su tiempo Platón, sino que el conocimiento lo adquiere del mundo sensible.

4 En realidad el término cuerpo puede tener, y tiene efectivamente, dos significados diversos en Aristóteles. A veces el cuerpo indica propiamente la materia que entra y es informada por el alma (forma del viviente). Otras veces por el contrario el término cuerpo indica directamente el organismo vivo (materia mas forma). Este doble significado será por otro lado una fuente permanente de equívocos y confusiones. Para ser lógico, Aristóteles debería haber hablado de materia y del alma; el alma informa a la materia y da de este modo origen a la existencia de un cuerpo; el cuerpo (vivo) es materia informada. En esta interpretación de las cosas el problema de las relaciones (extrínsecas) entre cuerpo y alma queda totalmente eliminado, ya que la materia y el alma no existen nunca como seres independientes. No son cosas ni seres, sino aspectos de un mismo compuesto viviente. Esta nota aparece en: (Gevaert, 2001, p. 75). 
Hasta aquí, Tomás de Aquino aún no separa al hombre de la categoría de la especie animal y lo pone en el mismo rango de las demás especies, quienes también están compuestas de alma y cuerpo.

Luego, en los seres naturales la materia es parte de la especie, aunque no la materia conformada, que es el principio de individuación, sino la materia común. Pues, así como es de esencia de este hombre el que conste de esta alma, de esta carne y de estos huesos, así también es de esencia del hombre el que conste de alma, de carne y de huesos, ya que a la sustancia específica debe pertenecer todo lo que comúnmente pertenece a las sustancias de los individuos contenidos en ella ${ }^{5}$. (De Aquino, 1 q. 75 a.4)

El hombre, en este sentido, no posee ninguna diferencia con los demás seres de su especie, los animales, porque el alma no es suficiente para definir ni contener la definición de hombre; es necesaria la intervención de un complemento, de otro compuesto con el que se pueda unir para realizar así todas sus funciones y operaciones; luego el hombre, en Tomas de Aquino, sólo se definirá como el compuesto y la integración sustancial entre espíritu y materia; es decir, entre alma y cuerpo. De este modo entonces:

Tomas de Aquino... insiste en el hecho de que hay en el hombre una doble unidad de cuerpo y alma: unidad de naturaleza y unidad de ser. Unidad de naturaleza, en cuanto que el hombre actúa como una sola naturaleza humana; unidad de ser, en cuanto que cada hombre es solamente un ser singular. Por tanto, el cuerpo y el alma espiritual no existen como dos seres, ni el hombre puede concebirse como la unión de dos seres que existen en un primer instante por cuenta propia. (Gevaert, 2001, p. 76)

Luego y si el hombre hasta aquí no se diferencia en su concepto de los demás animales de su especie, por estar al igual que ellos compuesto por alma y cuerpo: ¿Cuál será, entonces, el atributo que lo aleja de las demás especies animales?

5 "Unde materia est pars speciei in rebus naturalibus: non quidem materia signata, quae est principium individuationis; sed materia communis. Sicut enim de ratione "huius hominis" est quod sit ex hac anima et his carnibus et his ossibus; ita de ratione "hominis" est quod sit ex anima et carnibus et ossibus. Oportet enim de substantia speciei esse quidquid est communiter de substantia omnium individuorum sub specie contentorum". (De Aquino, 1 q. 75 a.4) 
Tomás de Aquino resuelve esta cuestión argumentando que el entendimiento se une al cuerpo a manera de forma, afirma que "el entendimiento, que es el principio de la operación intelectual, es la forma del cuerpo humano"6 (De Aquino, 1, q.75.4). Es decir, su alma. Así es como retomando ahora las palabras de su inspirador, dice Gevaert que Tomas de Aquino afirma que:

Ahora bien, la diferencia constitutiva del hombre es la racional que se dice del hombre por razón del principio intelectivo. Luego el principio intelectivo es la forma del hombre. Respondo que es necesario decir que el entendimiento que es principio de la operación intelectual, es la forma del cuerpo humano. (Gevaert, 2001, p. 77)

De este argumento se desprende que la definición de hombre realizada por Tomás de Aquino es profundamente Aristotélica, ya que él, define al hombre sustrayéndolo y separándolo de la definición que se hace de los demás seres vivientes, pues, si bien está compuesto, al igual que los demás animales, de alma y cuerpo, su alma, que es su forma, no será del mismo género, sino diferente a las de los demás animales. Por tanto la especie hombre es inmensamente diferente a las demás especies, por estar compuesta por otra clase de alma, que es la que le da la particularidad de ser animal racional y de diferenciarlo de las otras especies animales.

De ahí que digamos que el hombre es animal racional y no un compuesto de animal y de racional, como cuando decimos que lo es de alma y de cuerpo. Se dice que el hombre está compuesto de cuerpo y de alma, a la manera que se constituye una tercera cosa a partir de otras dos, la cual no es ninguna de estas. El hombre, por tanto, ni es alma ni cuerpo. Pero si se dice que el hombre está compuesto de algún modo de animal y de racional $^{7}$. (De Aquino, 1940, p. 64-65)

Esta forma que posee el hombre, y que lo hace diferente a los demás animales, es entonces, según lo dicho en la cita anterior, el alma intelectiva o racional que al igual

6 "Dicere quod intellectus, qui est intellectualis operationis principium, sit humani corporis forma". (De Aquino, 1, q.76 a.1)

7 "Unde dicimus hominem esse animal rationale, et non ex animali et rationali, sicut dicimus eum esse ex anima et corpore. Ex anima enim et corpore dicitur esse homo, sicut ex duabus rebús quaedam tertia res constituta, quae neutra illarum est. Homo enim neque est anima neque corpus. Sed, si homo aliquo modo ex animali et rationali ese dicatur...". (De Aquino, 1940, pp. 64-65). 
que en Aristóteles como en Tomás de Aquino, es en el hombre su principio de vida y principio de la intelección u operación intelectual.

Es de anotar, entonces, que el alma intelectiva por sí sola no define ni da el carácter sustancial al término hombre, es decir, el hombre no es el alma intelectiva o racional; por tanto, el alma no es el hombre. Ella no es por sí misma suficiente para contener y sustentar en solitario la categoría de ser humano; ella ha de estar integrada al cuerpo, a la materia que es el ente propio para conocer las cosas sensibles.

Otro de los argumentos que toma de su maestro y que refuerza su conjetura es el siguiente:

No queda, pues, admisible otra opinión que la de Aristóteles ${ }^{8}$ que establece que el hombre entiende porque el principio intelectivo es su forma; por consiguiente, resulta demostrado, por la operación misma del entendimiento, que el principio intelectivo está unido al cuerpo como su forma. También puede comprobarse lo mismo por la naturaleza de la especie humana, porque la naturaleza de cada cosa se manifiesta por su operación, la operación propia del hombre como hombre es la de entender, por la cual se sobrepone a todos los animales...

Es preciso, pues, según esto, que el hombre tome su especie de lo que es el principio de esta operación, y como lo que cada ser de la especie es la forma propia, síguese que el principio intelectivo es la forma propia del hombre ${ }^{9}$. (De Aquino, 1 q.76 a.1)

Queda claro que la especie hombre es diferente a la especie de los demás animales y a la de las demás especies y criaturas de la naturaleza, puesto que los procedimientos de su vida en particular se manifiestan a través de la operación del entendimiento

8 Véase: ARISTÓTELES. Acerca del alma, II 3, 415a 1-5.

9 "Relinquitur ergo solus modus quem Aristoteles ponit, quod hic homo intelligit, quia principium intellectivum est forma ipsius. Sic ergo ex ipsa operatione intellectus apparet quod intellectivum principium unitur corpori ut forma. Potest etiam idem manifestari ex ratione speciei humanae. Natura enim uniuscuiusque rei ex eius operatione ostenditur. Propria autem operatio hominis, inquantum est homo, est intelligere: per hanc enim omnia animalia transcendit...0portet ergo quod homo secundum illud speciem sortiatur, quod est huius operationis principium. Sortitur autem unumquodque speciem per propriam formam. Relinquitur ergo quod intellectivum principium sit propria hominis forma". DE AQUINO, Tomas. Suma Teológica.1 q.76 a.1. 
que es, como ya se ha mencionado, la operación vital del ser humano y que se realiza en virtud de la posesión de un alma particular y diferente a la de las demás especies de la tierra.

Es de entenderse, que el alma del hombre por ser intelectiva, es por excelencia el alma más desarrollada y perfecta, alejándose de las demás especies y convirtiéndose en una especie única y particular en comparación con las demás, con las que comparte el universo, ya que el alma del hombre tiene la virtud de entender y conocer todo lo sensible.

En virtud de la anterior afirmación, no se puede pensar que Tomás de Aquino niega en el hombre la existencia y la participación de las demás almas, diferentes a la intelectiva. Pues él, al retomar los argumentos de Aristóteles, defiende la idea de que en el ser humano además del alma intelectiva, participan otras almas que en esencia son diferentes a ésta. Existen, entonces, en el hombre otras almas diferentes, a saber: la sensitiva y la nutritiva, propia la primera de los animales y de las plantas, la segunda. Ahora bien, habrá que decir que estas almas en el hombre no aparecen de forma superpuesta o como un conjunto de almas que subyacen en él.

En otras palabras, el ser humano no está compuesto por una multiplicidad de almas, sino que son la misma: el alma intelectiva, el alma sensitiva y el alma vegetativa; así, y en palabras de Tomas de Aquino, el hombre sólo contiene en su ser como sustancia, una sola alma que está compuesta y alberga o contiene a todas las demás.

\begin{abstract}
Así, pues, el alma intelectiva contiene virtualmente cuanto hay en el alma sensitiva de los irracionales y en la vegetativa de las plantas. Por consiguiente, así como una superficie pentagonal no tiene una figura de cuadrilátero y otra de pentágono, ya que la primera sería superflua al estar contenida en el pentágono, así tampoco Sócrates es hombre y animal en virtud de otra, sino por razón de una sola y la misma alma ${ }^{10}$. (De Aquino, 1 q. 76 a.3)
\end{abstract}

10 Sic igitur anima intellectiva continet in sua virtute quidquid habet anima sensitiva brutorum, et nutritiva plantarum. Sicut ergo superficies quae habet figuram pentagonam, non per aliam figuram est tetragona, et per aliam pentagona; quia superflueret figura tetragona, ex quo in pentagona continetur; ita nec per aliam animam Socrates est homo, et per aliam animal, sed per unam et eandem". DE AOUINO, Tomas. Suma Teológica. 1 q. 76 a.3. 
Refiriéndose a este argumento de Tomas de Aquino, dice de nuevo Gevaert:

Para superar ulteriormente la apariencia de dualismo entre alma espiritual y cuerpo (vivo y organizado), Santo Tomas insiste en el hecho de que no hay un alma vegetativa y sensitiva distinta del alma espiritual. El alma espiritual, al tener una perfección superior, puede desarrollar todas las funciones del alma sensitiva y de la vegetativa. Hay por tanto en el hombre una sola alma, una forma sustancial, directamente responsable de todas las perfecciones que se manifiestan en el hombre... (Gevaert, 2001, p. 77)

Tomás de Aquino, como se ha argumentado, defiende la unidad hilemórfica del hombre, la misma que está fundada en la defensa de que el hombre forma una unidad, en la que hay una e inseparable forma esencial, el alma intelectiva, que constituye con la materia o el cuerpo una sustancia que compone, crea e integra el concepto "hombre o ser humano".

En este sentido, al igual que Aristóteles, Tomás de Aquino concibió la existencia de una sola y única alma en el hombre, que abarca e integra, tanto las funciones vegetativas como las sensitivas, y por ello es esta alma la que regula todas las funciones del "hombre" y la que determina su corporeidad.

\section{Influencia del concepto de hombre de la religión católica, en la visión de hombre de Tomás de Aquino}

En relación con la influencia bíblica y de la religión católica en las premisas de Tomás de Aquino sobre el hombre, es importante resaltar que aunque se ve influenciado por la teoría helimórfica de Aristóteles, tal explicación en relación con el surgimiento del alma, no le son suficientes al aquitano, debido a que sus reflexiones van un poco más allá, él trató de explicar y comprender los orígenes y los cimientos del alma, ya que como se ha dicho un poco más atrás, el alma como forma del cuerpo, no es una forma que pertenece a lo material, sino que ésta es de carácter espiritual, no dependiente ni en sus orígenes, ni en sus acciones, ni en su búsqueda del destino, de ninguna forma corpórea o terrenal. Entre otras la siguiente cita de Tomas de Aquino ilustra lo anteriormente planteado:

1. Aunque la sustancia espiritual no está comprendida en el cuerpo, éste de alguna forma lo alcanza, como hemos dicho. 
2. Entender es una operación del alma en cuanto supera los límites de la materia corporal, por eso no se realiza mediante un órgano corpóreo...

3. El alma tiene ser subsistente por cuanto su ser no depende del cuerpo, ya que es superior a la materia corporal.

4. El alma es forma del cuerpo por su propia esencia, no por algo añadido. De todos modos, en cuanto se relaciona con el cuerpo, es forma; mientras que, en cuanto supera los límites corporales, recibe el nombre de espíritu o sustancia espiritual ${ }^{11}$ (De Aquino, 2001, pp. 705-706).

A partir de estos argumentos, tomados de su propia experiencia, las claridades que sobre el tema le suministró el estudio de la Biblia y los alcances que sobre la cuestión se desarrollaron en la religión católica, Tomás de Aquino, saca la conclusión que el origen del alma no procede de una mera generación como ya lo había expresado su inspirador, sino que ésta tiene su origen en la creación divina, tal y como parece en uno de los pasajes del Génesis $(1,26)$.

Este argumento lo ilustra Coreht de la siguiente forma:

El cristiano sabe por la fe que el mundo no procede de una norma universal y necesaria; ni es tampoco el resultado de la evolución inmanente de una materia eterna, ni una emanación o desprendimiento metafísicamente necesario de Dios, es, más bien, producto de la libre palabra creadora de Dios que dijo “¡Hágase!” (Génesis 1,3). También la humanidad con su historia tiene su origen en la voluntad del creador: “¡Hagamos al hombre a nuestra imagen y semejanza! (Coreth, 1982, p. 52)

Esto “...constituye una de las geniales intuiciones del Aquinate que, recibiendo la herencia de la antigüedad, la Aristotélica en este caso, haciéndola suya, formula un sistema

11 "1.Ad primum ergo dicendum quod substantia spiritualis, licet non comprehendatur a corpore, attingitur tamen aliqualiter ab eo, ut dictum est. 2. Ad secundum dicendum quod intelligere est operatio animae humanae secundum quod superexcedit proportionem materiae corporalis, et ideo non fit per aliquod organum corporale. 3. Ad tertium dicendum quod anima habet esse subsistens, in quantum esse suum non dependet a corpore, utpote supra materiam corporalem elevatum. 4. Ad quartum dicendum quod anima secundum suam essentiam est forma corporis, et non secundum aliquid additum. Tamen in quantum attingitur a corpore, est forma; in quantum vero superexcedit corporis proportionem, dicitur spiritus, vel spiritualis substantia" (De Aquino, 2001, pp. 705-706). 
coherente al mismo tiempo que original, y en la perspectiva de la tradición cristiana" (Schmidt, 1994, p. 126).

Con los anteriores argumentos, retomados de la tradición griega, de la Biblia y la religión cristiana, Tomás de Aquino concluye y demuestra que los seres y los elementos de la naturaleza no nacen necesariamente de leyes universales, ni de un proceso material en permanente evolución. Ella es producto de un acto libre, benéfico y voluntario de la palabra divina de su creador quien en un acto generoso y amoroso hizo al hombre a su imagen y semejanza.

Estas reflexiones de la concepción cristiana y los argumentos de la definición de hombre de la tradición griega, toman en Tomás de Aquino, un nuevo valor:

El hombre se encuentra en el centro: entre el mundo material y sensible del cuerpo y el mundo espiritual y suprasensible... Es imagen y semejanza de Dios, el lugar de la trascendencia hacia Dios y está llamada a la vida inmortal. Tampoco se la entiende ya como pura razón, sino que al mismo tiempo es voluntad y facultad de libertad y amor. (Coreth, 1982, pp. 53-54)

Como se observa, si bien la teoría helimórfica de Aristóteles es la fuente primordial y de la que toma el aquinante sus argumentos sobre el hombre, éste se interesa por reflexionar la facultad más importante y relevante del hombre, la inteligencia. Facultad que lo hace diferente a las demás criaturas puestas sobre la tierra y que es en palabras de Tomás de Aquino la instancia más importante, pues es la que le facilita al hombre acercarse a la naturaleza divina. Dice entonces Tomás de Aquino:

Pues son superiores a las otras criaturas tanto por su perfección natural, como por su razón del fin. En cuanto a su perfección natural, porque únicamente la criatura racional tiene dominio de su acto, al actuar libremente; en cambio las demás criaturas, más bien que actuar, son actuadas, como ya hemos dicho. Y en cuanto a la dignidad de su fin, porque solo la criatura racional puede alcanzar mediante su actividad el mismo fin último del universo, o sea conocer y amar a Dios $^{12}$. (De Aquino, III, C. CXI)

12 "Praecellunt enim alias creaturas et in perfectioner naturae, et in dignitate finis. In perfectione quidem naturae, quia sola creatura rationalis habet dominium sui actus, libere se agens ad operandum; ceterae vero creaturae ad opera propria magis aguntur quam agant; ut ex supra dictis patet. In dignitate 
Así que, en primera instancia, dice García (2001), parece ser que la intelectualidad es el rasgo que acerca más a los hombres a la naturaleza divina, porque afirma que el hombre en cuanto es imagen de Dios, por ser de naturaleza intelectual, tiene la capacidad de entenderlo y de amarlo. Así mismo, afirma que el hombre posee en su ser otras operaciones que pueden ser también calificadas como divinas, ya que éstas no se realizan con la ayuda de las cualidades sensibles, ni por órganos corpóreos, sino que son llevados a cabo de manera espiritual. Estas opresiones se cifran en que el hombre es capaz de entender e imitar de la mejor manera las operaciones propias de Dios; de allí es que el hombre obtiene su perfección, es por esta razón que:

El hombre ocupa un puesto central en este universo: es imagen de Dios por la condición espiritual y está en el vértice de la condición corporal. El hombre reúne en sí mismo de modo como en un manojo, todas las perfecciones que están dispersas en las demás criaturas del universo... Y por eso se llama mundo menor, microcosmos, y se define como animal racional, y puede llamarse también espíritu encarnado, horizonte y confín, donde se encuentran los dos grados del ser, el espiritual y el corporal.

El puesto que Tomas le asigna al hombre en el universo ordenado es un puesto central, admirable... (Lobato, 1994, p. 126)

Es así como la escolástica en representación del aquinante toma y define al hombre como una criatura hecha a imagen y semejanza de Dios, en tanto ser racional y con capacidad intelectual que es, en suma, "la condición de posibilidad de la libertad humana, expresión culminante de la imagen divina en el hombre".(García, 2001, p. 637) De igual modo, "para Tomas de Aquino, gracias a su racionalidad la persona humana es capaz de obrar por sí misma y poseer dominio sobre su obrar, lo cual le dota de una singular dignidad". (García, 2001, p. 637)

Cabe entonces resaltar, que son estas concepciones sobre el hombre, acuñadas respectivamente por Aristóteles y Tomas de Aquino, las que aprovecha y utiliza Bartolomé de las Casas en todas sus discusiones y luchas a favor de la causa indígena. Son estos conceptos filosóficos de ser humano y de vida, que agregados a su vasta experiencia en América, lo que le da al defensor de los indios la capacidad para reflexionar el contexto en

autem finis, quia sola creatura intellectualis ad ipsum finem ultimum universisua operatione pertingit, sciticet cognoscendo et amando Deum." De Aquino, III, C. CXI). 
el que se llevó a cabo la conquista de América y acertar y salir avante en sus discusiones y reflexiones teóricas realizadas a favor de la raza indígena. Con ellas, se forma una idea de hombre y de la naturaleza humana de la cual se desprende y resultan algunas afirmaciones esenciales y propias de los hombres, que producen en ellos deberes y derechos.

En primera instancia, cabe entonces preguntarse ¿Cuál es el concepto de hombre en Bartolomé de las Casas?

\section{Concepto de hombre en Bartolomé de las Casas}

Las reflexiones y las teorías desarrolladas respecto del concepto de hombre por Las Casas, fueron inspiradas y cimentadas por una visión antropológica desligada no sólo de una notable reflexión filosófica, sino también de las experiencias que le dieron los numerosos viajes que hizo a las Américas y de las cuales tomó la siguiente visión de aquellas gentes:

Todas estas universas e infinitas gentes ${ }^{13}$, a todo género crió Dios las más simples, sin maldades ni dobleces, obedientísimas, fidelísimas a sus señores naturales y a los cristianos a quienes sirven, más humildes, más pacientes, mas pacíficas y quietas, sin rencillas ni bullicios, ni rijosos, ni querellosos, sin rencores, sin odios, sin desear venganza, que hay en el mundo virtuosos.

Son asimismo las gentes más delicadas, flacas y tiernas en complexión, y que menos pueden sufrir trabajo y que más fácilmente mueren de cualquier enfermedad; que ni hijos de príncipes y señores entre nosotros, criados en regalos y delicada vida, no son más delicados que ellos, aunque sea que entre ellos son de linaje de labradores. Son también gentes paupérrimas, y que menos poseen, ni quieren poseer de bienes temporales, y por esto no soberbias, no ambiciosas, no codiciosas. (De las Casas, 1941, p. 4)

13 Esta visión del hombre americano y con la que Bartolomé defendia el indio del nuevo mundo fue contrapuesto a la concepción y a las características que insensiblemente le habían dado algunos hombres de su raza y su época, y la cual es retomada por Gonzalo Fernández de Oviedo citado HANKE, Lewis por, "quien consideraba a los indios (igual que a los hispanoamericanos ciertos peninsulares) como: naturalmente vagos y viciosos, melancólicos, cobardes y en general gentes embusteras y holgazanas. Su ministerio no es un sacramento, sino un sacrilegio. Son idólatras, libidinosos y sodomitas. Su principal deseo es comer, beber, adorar ídolos paganos y cometer obscenidades bestiales. ¿Qué puede esperarse de una gente cuyos cráneos son tan gruesos y duros que los españoles tienen que tener cuidado con la lucha para no golpearlos en la cabeza, para que sus espadas no se emboten" (Hanke,1965. p. 15). 
Esta combinación entre teoría y práctica recogía en sí misma la tradición Aristotélica, la misma que fue plasmada y distribuida a lo largo y sin centrarse en una sola obra, en toda la tradición literaria de Bartolomé de las Casas, quien entrelazó y plasmó de manera dispersa los aportes más significativos que le suministró Aristóteles sobre el tema. En este marco de referencia se diría que el padre de Las Casas parte del concepto antropológico-filosófico de persona humana, nacida y sustraída principalmente de la filosofía Aristotélico-Tomista de pensamiento cristiano; teoría que le permite comprender que los indios, al igual que los españoles, tienen o están dotados sino de mejores, de iguales características y atribuciones que les permite, no sólo gozar de los mismos derechos, sino también considerárseles dignos y dotados de razón como todos y cada uno de los hombres. Así lo hace saber el defensor de los indios cuando afirma:

En resolución, aseveramos no solamente que es muy razonable admitir que nuestras naciones indígenas tengan diversos grados de inteligencia naturales el caso con los demás pueblos, sino que todas ellas están dotadas de verdadero ingenio; y más todavía, que en ellas hay individuos, y en mayor número que en los demás pueblos de la tierra, de entendimiento más avisado para la economía de la vida humana. Y que si alguna vez llega a faltar esta penetración o sutileza de ingenio, tal cosa sucede, sin duda alguna con el menor número de individuos, o mejor dicho, con un numero insignificante ${ }^{14}$. (De las Casas, 1975, p. 64)

Su lucha comienza a favor de los indios americanos al considerarlos como hombre y que como tal "está compuesto de cuerpo y alma espiritual, de acuerdo con la cual resulta una naturaleza humana a la que le adviene ciertos predicados esenciales propios que provocan derechos y deberes en los hombres" (Beuchot, 1994, p. 33).

Siguiendo con esta misma perspectiva antropológica, Las Casas descubre que al ser el hombre americano un ser dotado por naturaleza de un cuerpo y un alma, es poseedor de ciertas características y cualidades particulares que, siendo esenciales y propias, le impulsan a ser diferente a los demás hombres conocidos. No obstante

14 "Demum indiana nostra nationes oportere non solum diversos naturalis intelligentiae habere gradus, sicut accidit in allis, verum etiam omnes eas ingenio pollere, immo ut in pluribus quom in aliis mundi gentibus ingeniosiores ad régimen humanae vitae in eisdem reperiri; quod si ab hoc ingenii acumine seu subtilitate contingat deficere, hoc procul dubio in minori, quinimmo in minima evenice parte" (De Las Casas, 1975, p. 64). 
dichas características particulares de raza, color o situación, no le quitan en esencia la igualdad frente a los otros hombres "blancos", sino que cumple unánimemente y sin ser clasificado en niveles, la definición universal de ser un “animal racional”, por esto y como en todas las naciones del mundo, estos nuevos hombres descubiertos: cumplen la características fundamental de también ser hombres: Por ello y para Bartolomé de las Casas ninguna raza puede ser considerada con más privilegios que otra, o con mejores cualidades bajo el esquema de jerarquización. Esta razón de todos los hombres se manifiesta en:

Que todas las cosas que se han de hacer tocantes al bien de sí mismo, el hombre particular a su familia o casa, o a la ciudad o república, es necesario, que se presupone, que el hombre use de razón, como no hay quien de esto dude; y este uso de razón consiste: lo primero, que conozca y considere el fin y la razón del; lo segundo, que inquiera, discurra, y raciocinando busque los medios convenientes con el consejo, y lo que es bueno y provechoso para los negocios que ocurrieren, discerniendo y dividiéndolo también de lo que para ellos es nocivo y malo. Lo tercero, sentenciando, aprobando, admitiendo lo que conviene con el juicio, los cuales acto manifiesto es ser actos y operaciones propios de la razón y cognoscimiento del entendimiento y por consiguiente, de la prudencia, porque la prudencia presupone el entendimiento. (De las Casas, 1967, p. 214)

Que el hombre americano, esté dotado de razón, lleva a concluir que no existen entre estos y el hombre europeo, diferencias substanciales sino accidentales y que de este predicado esencial que es la definición, se sigue "la igualdad de los seres humanos de todos los pueblos y razas sin distinción" (Beuchot, 1994, p. 214). Y por ello, "la concepción de la universalidad del hombre que el padre Las Casas defendió tan tenazmente, es el fundamento de la trascendencia de su obra" (Esponda, 1994, p. 28). 


\section{Referencias}

Beuchot, M.(1994). Los fundamentos de los derechos humanos en Fray Bartolomé de las Casas. España: Anthropos.

Coreth, E. (1982). ¿Qué es el hombre?: Esquema de una antropología filosófica. Barcelona: Herber.

De Aquino, T. (1940). El ente y la esencia. Buenos Aires: Aguilar.

De Aquino, T. (2001). Opúsculos y cuestiones: selectas. Madrid: Biblioteca de Autores cristianos.

De Aquino, T. (1998). Suma contra los gentiles. México: Porrúa.

De Aquino, T. (1985). Suma Teológica: selección. Madrid: Espasa-Calpe.

De las Casas, B. (1967). Apologética Historia Sumaria. México: Universidad Nacional Autónoma de México, Instituto de Investigaciones Históricas.

De las Casas, B. (1975). Del único modo de atraer a todos los pueblos a la verdadera religión. México: Fondo de cultura económica.

De las Casas, B. (1941). Doctrina. México: Ediciones de la Universidad Nacional Autónoma de México.

Esponda, V. (1994). Algunas reflexiones acerca de los estudios lascanianos. En: Gonzales, H. et al. (1994) El pensamiento lascaniano en la conciencia de América y Europa. México: Universidad Nacional Autónoma de México Centro de Investigaciones humanísticas de Mesoamérica y el estado de Chiapas.

García, J. (2001). El fundamento de la imagen de Dios en el hombre. Interpretación de D. Bañes a la Doctrina tomista. Revista Anuario Filosófico, 35(3), 633-654.

Gevaert, J. (2001). El problema del hombre. Introducción a la Antropología filosófica. Salamanca: Sígueme.

Lobato, A, Segura, A. y Forment, E. (1994). El hombre en cuerpo y alma. Valencia: Edicep.

Platón. (1992). Diálogos. Tomo III. Bogotá: graficas Modernas. 
Romo, P. (1994). Las filosóficas del pensamiento de Fray Bartolomé de las Casas. En: Gonzales, H. et al. El pensamiento lascaniano en la conciencia de América y Europa. (pp.149-164). México: Universidad Nacional Autónoma de México Centro de Investigaciones humanísticas de Mesoamérica y el estado de Chiapas.

Scheler, M. (1989). La Idea del Hombre y la Historia. Buenos Aires: Siglo Veinte.

Schmidt, A. (1994). Santo Tomas y el de Anima (Comentario a los caps. 4 y 5 del libro III del De Anima de Aristóteles). Revista Analogía Filosófica, 8(1), 123-137. 